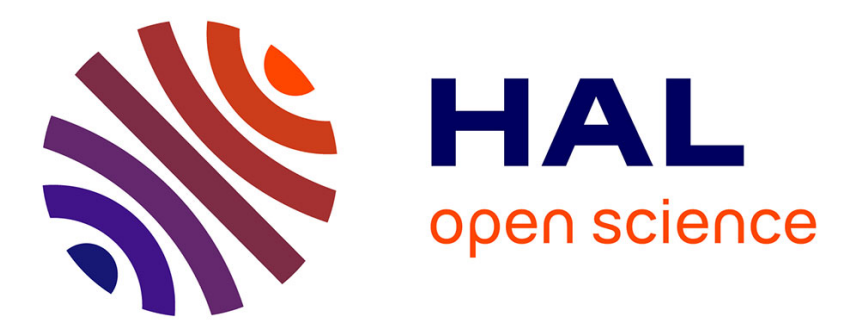

\title{
Opto-thermal technique for in-vivo stratum corneum hydration measurement
}

\author{
R. Bindra, R. Imhof, A. Mochan, G. Eccleston
}

\section{To cite this version:}

R. Bindra, R. Imhof, A. Mochan, G. Eccleston. Opto-thermal technique for in-vivo stratum corneum hydration measurement. Journal de Physique IV Proceedings, 1994, 04 (C7), pp.C7-465-C7-468. 10.1051/jp4:19947108 . jpa-00253160

\section{HAL Id: jpa-00253160 https://hal.science/jpa-00253160}

Submitted on 1 Jan 1994

HAL is a multi-disciplinary open access archive for the deposit and dissemination of scientific research documents, whether they are published or not. The documents may come from teaching and research institutions in France or abroad, or from public or private research centers.
L'archive ouverte pluridisciplinaire HAL, est destinée au dépôt et à la diffusion de documents scientifiques de niveau recherche, publiés ou non, émanant des établissements d'enseignement et de recherche français ou étrangers, des laboratoires publics ou privés. 


\title{
Opto-thermal technique for in-vivo stratum corneum hydration measurement
}

\author{
R.M.S. Bindra, R.E. Imhof, A. Mochan and G.M. Eccleston* \\ Department of Physics and Applied Physics, Strathclyde University, Glasgow G4 ONG, U.K. \\ * Department of Pharmacological Sciences, Strathclyde University, Glasgow G4 ONG, U.K.
}

\begin{abstract}
A new method for measuring stratum corneum hydration in-vivo, using opto-thermal transient emission radiometry with $2.94 \mu \mathrm{m}$ Er:YAG excitation and wavelength selective detection, is described. Results on skin recovery following exogenous hydration, skin stripping with Sellotape and wound healing are presented.
\end{abstract}

\section{INTRODUCTION}

Stratum corneum hydration, though an important property of human skin with regard to feel, look and dermatological disorders, is difficult to measure in-vivo. Current methods are mostly indirect, as with trans-epidermal water loss or viscoelastic measurements, or have poor reproducibility because of interference by other parameters to which the measurement is sensitive, as with electrical impedance methods (eg [1]). The requirement for physical contact with the skin introduces additional systematic errors through the disruption of natural transpiration. The remote sensing capability of opto-thermal transient emission radiometry, or $O T T E R$, has the potential to overcome these limitations. However, first studies of opto-thermal hydration effects [2-3] showed low sensitivity and specificity, because water is transparent at the visible and UV excitation wavelengths used.

The technique reported here exploits the spectral properties of water [4] to maximise sensitivity to hydration. It uses an excitation wavelength of $\lambda_{e x}=2.94 \mu \mathrm{m}$ from a Q-switched Er:YAG laser, close to the main absorption peak, $\alpha=1.3 \times 10^{6} \mathrm{~m}^{-1}$, of water. The wavelength of the emitted thermal radiation is similarly selected to one of strong water absorption of $\beta \sim 3 \times 10^{5} \mathrm{~m}^{-1}$ by using interference filters of centre wavelength $\lambda_{e m}=6.05 \mu \mathrm{m}$ or $\lambda_{e m}=13 \mu \mathrm{m}$. Targeting water in this way has the further benefit of reducing the sensitivity of the measurements to variations of skin type, site, colouration and externally applied substances.

\section{THEORY}

The use of excitation and thermal emission wavelengths that are strongly absorbed in the top few microns of the stratum corneum simplifies the theoretical description of the resultant opto-thermal signal. Lower skin layers are not reached by the excitation, nor can their radiation reach the detector. The effect of thermal wave reflection from lower layers is small, because of the low thermal diffusivity of skin $\left(1.7-12 \times 10^{-8} \mathrm{~m}^{2} \mathrm{~s}^{-1}\right.$, depending on hydration [5]). Optical scattering can be neglected, not only because of the dominance of absorption, but also because of the low turbidity of skin at the long wavelengths used.

For these reasons, the opto-thermal response of the stratum corneum observed as above resembles that of a semi-infinite homogeneous material. Furthermore, since $\alpha>\beta$, the excitation is in photothermal 
saturation and the signal $S(t)$ can be described by [6]

$$
S(t)=A e^{t / \tau} \operatorname{erfc}(\sqrt{t / \tau}) \quad \text { where } \quad \tau=\frac{1}{\beta^{2} D}
$$

where $\boldsymbol{A}$ is a constant, $\tau$ is the opto-thermal decay time and $\boldsymbol{D}$ the thermal diffusivity.

The method characterises skin hydration with a single parameter, the opto-thermal decay time, which is simple to measure in-vivo, because it is insensitive to experimental parameters such as energy absorbed or optical alignment. It is related to two fundamental physical parameters, $\beta$ and $D$, and is therefore capable of absolute calibration, once their dependence on hydration are known.

\section{RESULTS}

The measurements were performed with a conventional OTTER apparatus [7] using a mechanically Q-switched Er:YAG laser manufactured to our specifications by Spectron Lasers Ltd. It produces pulses of $2.94 \mu \mathrm{m}$ wavelength, $\approx 100 \mathrm{~ns}$ duration and $4 \mathrm{~Hz}$ repetition frequency. Thermal emissions were selected with interference filters of either $6.05 \mu \mathrm{m} \quad(280 \mathrm{~nm}$ passband) or $13 \mu \mathrm{m}$ (1.4 $\mu \mathrm{m}$ passband) centre wavelength and detected with a liquid nitrogen cooled Mercury Cadmium Telluride detector. Before each experiment, the skin was prepared by washing thoroughly with bar soap and allowing it to recover for half an hour in the laboratory. Skin hydration experiments were performed on the ventral surface of the first finger of volunteers hydrated exogenously by prolonged immersion in water, until wrinkled. Measurements of full hydration were performed within one minute of withdrawal, after swabbing the finger dry.

\subsection{Method Verification}

The sensitivity of the method to stratum corneum

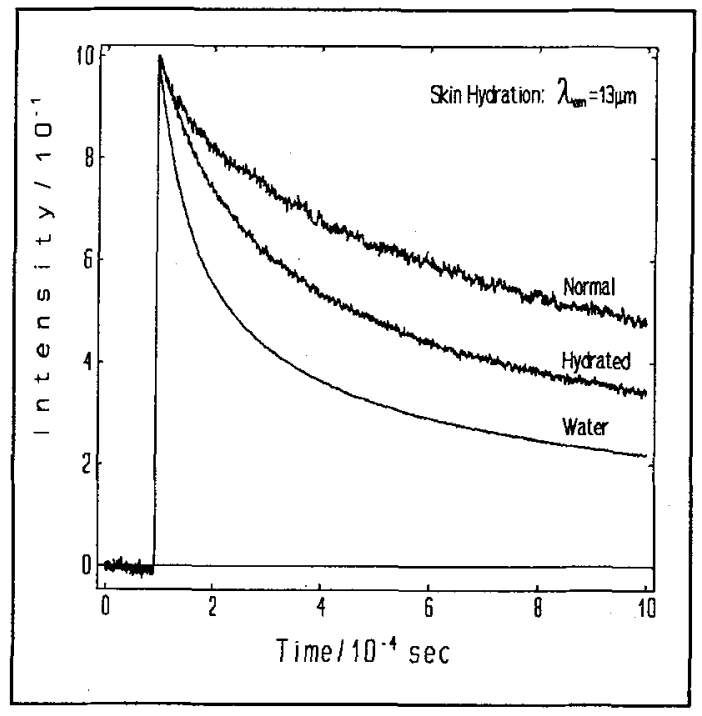

Figure 1: Opto-thermal impulse response curves for normal and hydrated skin, compared with that for distilled water. hydration is illustrated in Figure 1. Opto-thermal impulse response curves for normal and hydrated skin are compared with that for distilled water, all observed with a thermal emission wavelength of $13 \mu \mathrm{m}$. The increase in noise level of the (normalised) impulse response curves with decreasing water content confirms that the signals emanate predominantly from water. Least-squares analysis confirmed that the curves conform closely to the theoretical model of Eq.(1), yielding opto-thermal decay times of $0.7 \mathrm{~ms}$ and $0.3 \mathrm{~ms}$ for normal and hydrated skin, and $80 \mu \mathrm{s}$ for water.

Studies of many volunteers and skin sites revealed that the opto-thermal decay time for fully hydrated skin observed at $13 \mu \mathrm{m}$ thermal emission wavelength is nearly constant, $\tau_{F H}=300 \pm 20 \mu \mathrm{s}$. This was used as one fixed point of a rough and ready calibration formula

$$
H=90 \tau_{F H} / \tau
$$

where in-vitro stratum corneum thermal diffusivity data [5] were used to infer a value of $\boldsymbol{H} \approx \mathbf{9 0 \%}$ for fully hydrated skin. The other fixed point is $\boldsymbol{H}=0 \%$ as $\boldsymbol{\tau} \rightarrow \infty$.

The method also works well with $\lambda_{e m}=6.05 \mu \mathrm{m}$, where water has a sharp absorption peak of similar 
absorbance value to that at $13 \mu \mathrm{m}$. However, its overlap with a spectral feature from skin itself, together with the rapid variation of $\beta$ near $\lambda_{e m}=6.05 \mu \mathrm{m}$, lead to a somewhat poorer conformance of the $\lambda_{e m}=6.05 \mu \mathrm{m}$ impulse response curves to the above model. For this reason, $\lambda_{e m}=13 \mu \mathrm{m}$ was sometimes preferred over $\lambda_{e m}=6.05 \mu \mathrm{m}$, despite the higher signal strength and better defined $\tau_{F H}=30 \pm 1 \mu \mathrm{s}$ of the latter. Experiments in the low absorbance region $\lambda_{e m}=7-10 \mu \mathrm{m}$ gave a much lower sensitivity to hydration, with evidence of signal contributions from layers beneath the stratum corneum, similar to those observed with $\lambda_{e x}=355 \mathrm{~nm}$ at all emission wavelengths [2-3].

\subsection{Hydration Recovery}

The method was used to measure the rate of recovery of fully hydrated skin under normal laboratory conditions. The results are shown in Figure 2. An exponential curve fitted to these data gives a $1 / \mathrm{e}$ recovery time of $22 \mathrm{~min}$ for laboratory conditions of $16^{\circ} \mathrm{C}$ and $44 \%$ relative humidity.

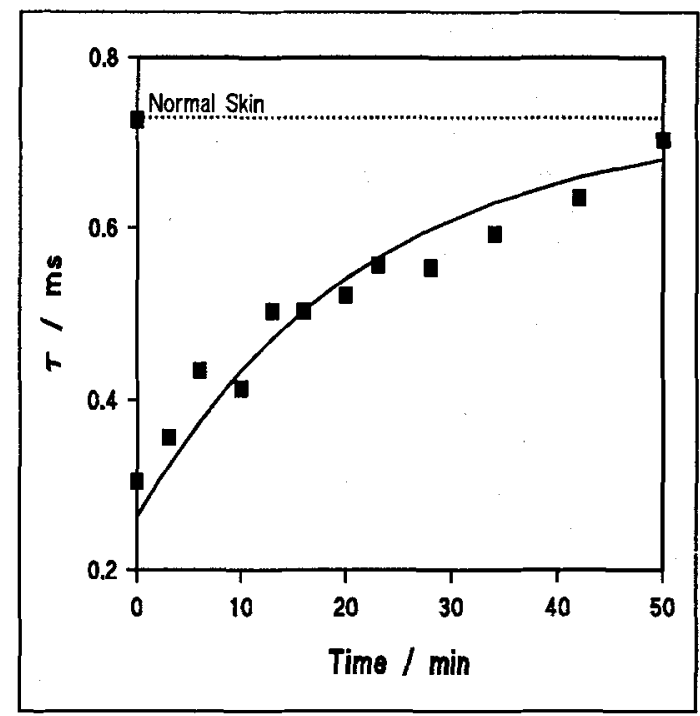

Figure 2: Recovery following exogenous hydration of a finger, measured using $\lambda_{e m}=13 \mu \mathrm{m}$.

\subsection{Tape Stripping}

Transdermal water loss is known to increase with the removal of stratum corneum from live skin. This was confirmed in a series of hydration measurements following tape stripping with Sellotape on the ventral surface of the forearm of volunteer RMSB. The results are presented in Figure 3. The thickness of stratum corneum removed in each of the first four applications of the tape was measured to be in the range $1-2 \mu \mathrm{m}$. Each removal was found to produce a small increase of hydration. The fifth strip removed

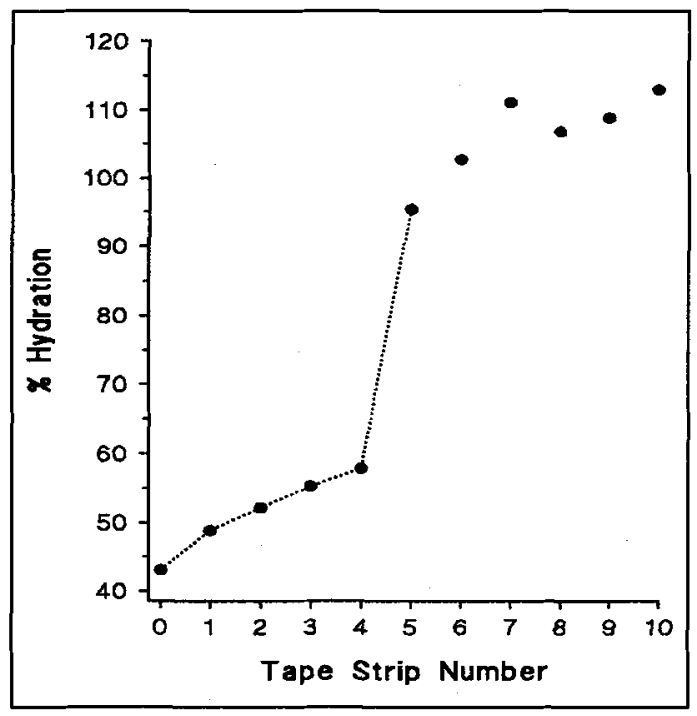

Figure 3: Hydration measurements during tape stripping of a ventral forearm site.

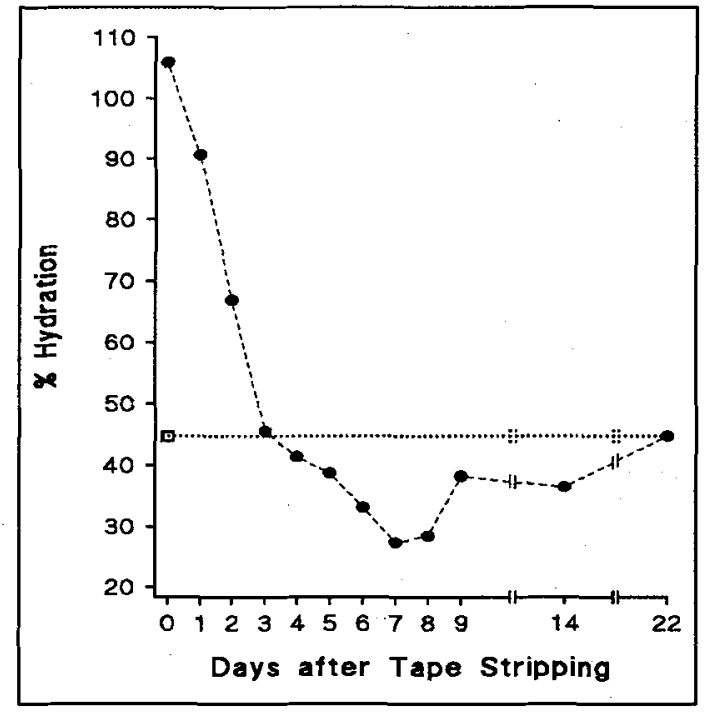

Figure 4: Hydration changes during the healing of a tape strip wound. The dotted line is hydration prior to stripping. 
a stratum corneum thickness of $\approx 8 \mu \mathrm{m}$ and led to a greatly increased rate of transdermal water loss, with the skin looking moist and the measurement indicating full hydration. Further applications of the tape removed little and produced hydration measurements in excess of $100 \%$, presumably because of the build-up of residues.

\subsection{Wound Healing}

The healing of the wound produced by tape stripping experiments reported in Section 3.3 above was monitored over a period of 22 days, as illustrated in Figure 4 . The fully hydrated condition of the freshly produced wound was found to recover to normal levels and below within the first few days, as a callus formed, which dried and was shed on the tenth day. The new stratum corneum formed beneath the callus was found to be slightly less hydrated than normal, but recovered towards normal levels in the ensuing several days.

Hydration changes associated with the healing of a different kind of wound, a burn on the ventral surface of a finger, are shown in Figure 5. These

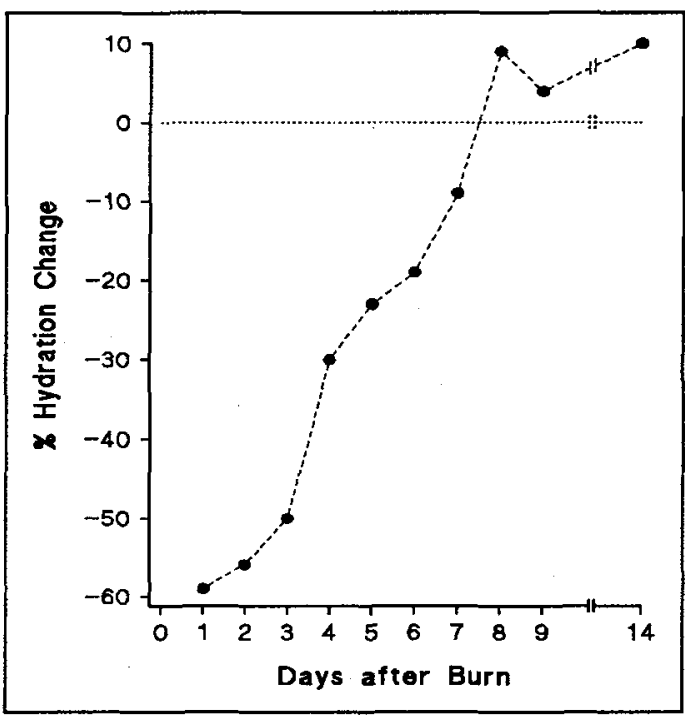

Figure 5: Changes of hydration during the healing of a burn wound, normalised against a neighbouring healthy site. measurements proved less straightforward, because of the much larger underlying variability of skin hydration of the fingers with temperature, relative humidity and prior activity of the individual. However, consistent results were produced by calculating changes of hydration of the area of interest, compared with the hydration of a neighbouring healthy skin site, measured at the same time. In this case the hydration of the fresh wound was found to be much lower than normal. Its recovery was found to be progressive, without the formation of a callus.

\section{CONCLUSIONS}

Skin hydration in-vivo can be measured non-invasively using OTTER with $2.94 \mu \mathrm{m}$ excitation wavelength and either $6.05 \mu \mathrm{m}$ or $13 \mu \mathrm{m}$ thermal emission wavelength. Work is now in progress to relate the measured opto-thermal decay times to the physical properties of the stratum corneum, to improve theoretical understanding, and to study hydration changes in the presence of externally applied substances.

\section{Acknowledgment}

We thank the SERC, Unilever and the Health \& Safety Executive for research support and John Reevie for his invaluable technical assistance.

\section{References}

[1] Potts R.O. J.Soc.Cosmet.Chem. 37(1986) 9-33.

[2] Bindra R.M.S. Eccleston G.M. Imhof R.E. and Birch D.J.S. (Photoacoustic and Photothermal Phenomena III(1992) Editor: Bicanic D. Springer Series in Optical Sciences 69) 95-99.

[3] Bindra R.M.S. Imhof R.E. Eccleston G.M. and Birch D.J.S. SPIE Proc. 1643(1992) 299-309.

[4] Hale G.M. and Querry M.R. Appl.Opt. 12(1973) 555-563.

[5] Brown S.M. Baes M.L. Shen J. and Snook R.D. Anal.Chim.Acta 282(1993) 711-719.

[6] Imhof R.E. Zhang B, and Birch D.J.S. (Progress in Photothermal and Photoacoustic Science and Technology II, Editor: Mandelis A. PTR Prentice Hall, Englewood Cliffs 1994) 185-236.

[7] Imhof R.E. Whitters C.J. and Birch D.J.S. Phys.Med.Biol. 35(1990) 95-102. 